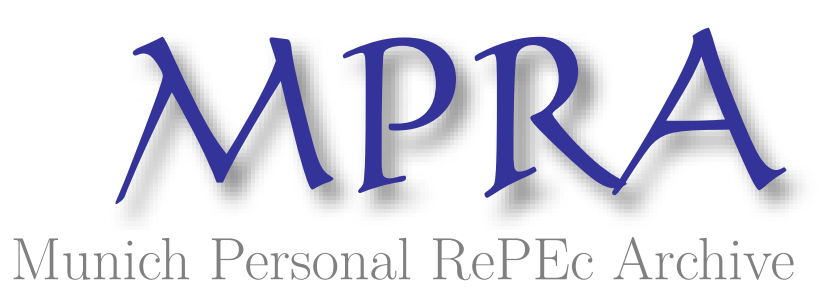

\title{
Transnational Policing: Preemption and Deterrence against Elusive Perpetrators
}

Nakao, Keisuke

12 July 2016

Online at https://mpra.ub.uni-muenchen.de/72676/

MPRA Paper No. 72676, posted 25 Jul 2016 13:29 UTC 


\title{
Transnational Policing:
}

\section{Preemption and Deterrence against Elusive Perpetrators*}

\author{
Keisuke Nakao ${ }^{\dagger}$
}

\begin{abstract}
Why does a state directly police certain kinds of transnational perpetrators by itself while indirectly policing other kinds through their host government? To address this question, we develop a formal model, where Defender chooses either to police Perpetrators or to make Proxy do so. According to our theory, the delegation of policing can enhance its effectiveness in light of Proxy's advantages in threatening, identifying, and attacking Perpetrators, but it may also cause inefficiency if Defender has limited information about Proxy's choice or cost of policing. Depending on the relative size between these advantages and disadvantages, one of the following four forms of policing may emerge: (i) Defender polices Perpetrators on her own (e.g., Somali counter-piracy operations); (ii) Defender induces Proxy to police Perpetrators (U.S. War on Drugs); (iii) Defender and Proxy together police Perpetrators (Operation Inherent Resolve); (iv) two or more Defender-Proxy states police Perpetrators in each's own domain (Interpol).
\end{abstract}

Keywords: cyberattack, deterrence, policing, piracy, preemption, terrorism

JEL classifications: F51, 52, 53; H56, 77; K42

Word count: 10,540

\footnotetext{
* Acknowledgment: I thank Masatoshi Tsumagari, Hiroshi Uno, Yoshinao Sahashi, Yukari Iwanami, Yasutomo Murasawa, and Su-Mi Lee for their helpful comments. I also thank Osaka Prefecture University for its hospitality during my stay in 2014/2015. Earlier versions of this article were presented at Osaka Prefecture University and Konan University. All errors are my own.

${ }^{\dagger}$ College of Business and Economics, University of Hawaii at Hilo, 200 W. Kawili St., Hilo, HI, USA. E-mail: keisuken@hawaii.edu.
} 


\section{Introduction}

In the late fourteenth century, China's Ming dynasty was annoyed by persistent raids by Japanese pirates along the Chinese coast. Successive emperors attempted to crack down on them but ultimately failed, as the pirates were too agile, remote, and hence elusive. In its search for an alternative countermeasure, the Ming dynasty, on several occasions, dispatched envoys to Japan's secular Muromachi shogunate. In exchange for a tributary status that actually brought enormous economic profits to the Japanese shogunate, China requested Japan to suppress the piracy. In response, Japan's shogunate arrested some pirate chieftains and submitted them to the Ming court (Tanaka 2012: 76). Shortly after the so-called tally trade was initiated between the two countries, piratical activities waned substantially (Mote 1999: 720). This is a practice of indirect policing that this article is wholly concerned with.

Instances of indirect policing can also be found in the contemporary period. The increasing consumption of illegal drugs has been a long-standing concern for the U.S. To curb the supply of drugs in an effective manner, the U.S. forged security partnerships with Colombia and Mexico, both of which were major roots and routes of narcotic trafficking (Plan Colombia and Merida Initiative). These partnerships aimed at assisting the governments of Colombia and Mexico financially and militarily in their campaigns against drug cartels. ${ }^{1}$

These two episodes suggest that even a superpower has to rely on a third party to wipe out transnational perpetrators if they are harbored beyond its reach. The very reason for its reliance is the third party's influence over transnational perpetrators. However, indirect policing is not always functional.

In its pursuit of Operation Enduring Freedom, for instance, the U.S. deployed combat drones in Pakistan's Federally Administered Tribal Areas (FATA), Yemen, and Somalia, instead of relying on the sovereign authorities of these regions, to defeat al-Qaeda, Taliban, and their associates (Scahill 2013). Despite accumulating collateral damages and accompanying protests from the local populace, the U.S. has still been fixated on the drone tactics there. ${ }^{2}$ In contrast with the indirect form, we call this direct policing, whereby the targeted or victimized state itself conducts security campaigns against perpetrators. Recent counter-piracy campaigns to protect merchant vessels off the Somali coast constitute another instance of direct policing (Combined Task Force 151). ${ }^{3}$

\footnotetext{
${ }^{1}$ Evaluations of the partnerships are disputed. For criticism of Plan Colombia, see Isacson 2005; Stokes 2005; of Merida Initiative, see Olson and Wilson 2010; of War on Drugs in general, see Reuter, Crawford, and Cave 1988.

2 The U.S. is helping to breed a new generation of enemies in Somalia, Yemen, Pakistan, Afghanistan and throughout the Muslim world (Scahill 2013: 104, 177, 518).

${ }^{3}$ Since the U.N. Security Council Resolution 1816 was adopted in 2008, the Permanent Five and several other
} 
A comparison of indirect and direct policing raises thought-provoking questions, which we will tackle in this article. Why do we observe indirect policing in some instances but direct policing in others? When does indirect policing outperform direct policing, and vice versa? If the third party's influence is really the reason to adopt indirect policing, what are the sources of the influence? Meanwhile, what makes direct policing difficult? In parallel, if the lack of the third party's influence is the reason to pursue direct policing (despite little strategic success), why does the targeted state not make the third party influential through financial and/or military assistance?

To address these questions, we have developed a game-theoretic model that delineates interactions among Defender, Proxy, and Perpetrators. ${ }^{4}$ Defender is a state government that is targeted or victimized by Perpetrators; Proxy is a state government that hosts Perpetrators; ${ }^{5}$ Perpetrators are non-state individuals, networks, and organizations that aim to infringe on Defender's interests transnationally. We say that indirect policing operates if Defender induces Proxy to police Perpetrators. By analyzing the model, we aim to uncover the mechanism of indirect policing. Namely, we will pin down the obstacles to direct policing and illustrate how indirect policing can overcome the obstacles. In contrast, the literature merely posits that indirect deterrence (connoting indirect policing in our language) can work because it exploits a third party's influence—without formally investigating the sources of its influence (Bar 2008; George 2002; Knopf 2012; Smelser and Mitchell 2002; Trager \& Zagorcheva 2005/06; Wilner 2011). ${ }^{6}$ What we mean by indirect policing is closely related to indirect deterrence but with a sharp distinction. We term it policing to refer to the combination of preemption and deterrence. Preemption means a proactive counterforce attack whose impacts are physical, while deterrence means a reactive countervalue attack in which psychological influence is expected (Freedman 2004: 84-108; Sandler and Siqueira 2006). In Schelling's (1966: 2-6) words, preemption is an application of brute force that aims to

states have sent their navies to the Gulf of Aden.

${ }^{4}$ Throughout the article, we assign the feminine pronoun ("she") to Defender, the masculine one ("he") to Proxy, and the plural one ("they") to Perpetrators, respectively.

${ }^{5}$ We restrict our scenarios such that only the state government hosting Perpetrators assumes Proxy. For the host state's roles and influence, see Carter 2012; Heymann 2001/02. Candidates for Proxy, other than a sovereign state, include privateers (e.g., Captain Kidd), religious authorities (ulama, rabbi), local leaders (chieftain, clan head, emir, lord, patriarch, raja), patrons, peers, or kinsmen who can exert some influence on Perpetrators. When Proxy is hostile to Defender, indirect policing is difficult (Salehyan 2009). For discussion on Proxy candidates, see Colby 2008; Davis and Jenkins 2002, 2004; Whiteneck 2005.

${ }^{6}$ A synonym for indirect deterrence is expanded deterrence, which "encompass[es] not only those directly involved in a terror plot, but those individuals, governments, or other entities whose material support, cooperation, complicity, or gross negligence enabled an attack" (Colby 2008). Triadic deterrence is another synonym (Atzili and Pearlman 2012). A tactic to deter moderate elements within the adversary's system also resembles indirect deterrence (Davis and Jenkins 2002, 2004; Miller 2013; Whiteneck 2005). 
cripple adversaries, while deterrence is a form of coercion that aims to threaten them (Table 1). When indirect policing is adopted, Defender (e.g., Ming China in the lead episode) may not observe whether Proxy (Muromachi Japan) actually adopts preemption or deterrence. Defender may not care about the means of policing but merely about the consequence. Thus, what is practiced indirectly is not necessarily deterrence but possibly preemption. However, the literature on indirect deterrence seems unconscious of the distinction between them. Moreover, what we have observed across the Third World, especially in Afghanistan, Pakistan, and Iraq, since the 9/11 attacks imply failures of deterrence-the military has been engaged and violence exchanged for so long (Kroenig and Pavel 2012: 24). Although indirect policing is far from rare, it remains surprisingly understudied. For these reasons, we espouse "policing" rather than "deterrence" to express what we address throughout the article.

Given the prevalence of policing against transnational perpetrators, we categorize policing into four forms, associating each with historical and contemporary incidents. Policing is called: (i) direct if it is conducted solely by Defender (e.g., U.S. drone strikes in Pakistan, Yemen, and Somalia, Operation Neptune Spear, Somali counter-piracy); (ii) indirect if it is solely by Proxy (e.g., U.S. War on Drugs in Colombia and Mexico, Operation Enduring Freedom - Philippines); (iii) joint if it is by both Defender and Proxy (e.g., Operation Inherent Resolve; Israel-Palestine relations after the Second Intifada, medieval China-Japan alliance against Japanese pirates); and (iv) reciprocal if it is divisibly and multilaterally fulfilled by several Defender-Proxy states (e.g., Interpol, Five Eyes, Budapest Convention, Shanghai Cooperation Organization, U.S. Fugitive Slave Laws). We then deliver the conditions under which different forms of policing are adopted.

Our work's contribution to the literature can be summarized in threefold.

First, while existing analyses of indirect deterrence and the like lack formal rational-choice grounds (Atzili and Pearlman 2012; Bar 2008; Carter 2012; Colby 2008; Davis and Jenkins 2002, 2004; George 2002; Heymann 2001/02; Knopf 2008, 2012; Smelser and Mitchell 2002; Trager and Zagorcheva 2005/06; Whiteneck 2005; Wilner 2011), we develop a game-theoretic model to depict the strategic interaction among Defender, Proxy, and Perpetrators. In doing so, we exploit theories of deterrence, repeated games, and principal agent.

Second, unlike the literature on indirect deterrence, we study situations where Defender may combine preemption with deterrence. We believe that our theory better captures the situation where a government fails to deter some Perpetrators and is forced to fight them (e.g., U.S. War on Terrorism). Notable theoretical work on preemption and deterrence is Sandler and Siqueira (2006), who emphasize 
substitutive aspects of preemption and deterrence. In contrast, we treat them as complementary countermeasures (Table 1$)^{7}$

Third, our analyses pertain not just to indirect policing, but also to three other forms. Instead of appraising indirect policing unconditionally, we seek to explore its disadvantages as well as advantages to explain why Defender sometimes adopts direct policing (e.g., U.S. drones strikes against terrorists) rather than indirect counterpart. By delivering the condition for each of these forms, we address why one of them appears better than others in a given situation.

The rest of the article proceeds as follows. After presenting an informal theory on deterrence against perpetrators, we develop a game-theoretic model that formulates the four forms of transnational policing. We then elucidate the advantages and disadvantages of each policing form and subsequently offer incidents of policing. In conclusion, we summarize our theoretical findings.

Table 1. Two forms of policing

\begin{tabular}{|c|c|c|}
\hline & Preemption & Deterrence \\
\hline Means & $\begin{array}{c}\text { Crippling } \\
\text { (brute force) }\end{array}$ & $\begin{array}{l}\text { Threatening } \\
\text { (coercive force) }\end{array}$ \\
\hline Form of force & Forestallment & Punishment \\
\hline Timing of applying force & $\begin{array}{l}\text { Before perpetration } \\
\text { (proactive) }\end{array}$ & $\begin{array}{l}\text { After perpetration } \\
\text { (reactive) }\end{array}$ \\
\hline Target of force & $\begin{array}{c}\text { Means of perpetration } \\
\text { (counterforce) }\end{array}$ & $\begin{array}{l}\text { Value to hold dear } \\
\text { (countervalue) }\end{array}$ \\
\hline Influence & $\begin{array}{l}\text { On capability } \\
\text { (physical) }\end{array}$ & $\begin{array}{l}\text { On decision calculus } \\
\text { (psychological) }\end{array}$ \\
\hline Communication & Unnecessary & $\begin{array}{c}\text { Terms and severity } \\
\text { of punishment }\end{array}$ \\
\hline
\end{tabular}

\footnotetext{
7 A more thorough discussion on preemption and deterrence appears in Online Appendix.
} 


\section{Theory of Deterrence against Perpetrators}

Before introducing the formal model, we informally theorize deterrence against perpetrators, based upon classical deterrence theory and its criticisms (Bowen 2004: 59; Harvey 1998; Lebow 1981: 85-89; Levy 1988: 486; Wilner 2011: 31). We maintain that deterrence against perpetrators (such as crackers, pirates, and terrorist networks) comprises the following three tasks:

1. Threatening. Defender communicates to Perpetrators the threat of punishment that will precipitate if Perpetrators infringe on her interests. By doing so, Defender attempts to manipulate Perpetrators' incentives.

2. Investigation. When faced with an act of aggression, Defender identifies the culprit and determines the target of punishment.

3. Punishment. Defender inflicts a punitive charge against the culprit.

If Perpetrators rationally make their decisions based on cost-benefit calculus, they can be deterred if the punishment is sufficiently severe and credible. To fulfill these tasks, Defender must possess the following four qualifications:

- Resolve (Commitment). Defender has the resolve to retaliate if deterrence fails.

- Communication. Defender can convince Perpetrators of her resolve and capability of imposing the punishment.

- Intelligence. Defender is capable of identifying the culprit and finding out what he holds dear with sufficient likelihood (Bowen 2004: 68; Gray 2003, 453; Levy 1988; Wilner 2011: 31).

- Capability. Defender has the means to inflict unbearable damages on Attacker.

Moreover, for Defender to implement the three tasks above, three qualifications for Perpetrators as deterrees are also needed, as listed below:

- Unity. Perpetrators are well-centralized and organized that they can make and carry through a collective decision as if they were a unitary actor. Otherwise, even when their leadership is deterred, their peripheral elements may not be (Miller 2013; Sageman 2004: 167, 172-173; Sageman 2008).

- Visibility. Perpetrators retain a certain degree of transparency in that if aggression takes place, Perpetrators can be identified with sufficient likelihood, and their return addresses detected.

- Return address. Perpetrators have a sizable and damageable value to hold dear. ${ }^{8}$

The discussion above is a modification of classical deterrence theory that overlooks the necessity of

\footnotetext{
${ }^{8}$ Some perpetrators are so fanatical that they have no or little secular value to hold dear (Betts 2002; Knopf 2008: 229; Trager and Zagorcheva 2005/05: 87; Wilner 2011: 4).
} 
intelligence as the deterrer's qualification as well as unity, visibility, and return address as the deterree's qualifications (Bowen 2004: 59; Harvey 1998; Lebow 1981: 85-89; Levy 1988: 486; Wilner 2011: 31). This is presumably because the targets of U.S. deterrence during the Cold-War era were almost exclusively overt adversaries - the Soviet Union and its allies—which trivially met these qualifications. However, these qualifications have attracted attention in recent decades, because scholars and policymakers have shifted their attention from the Cold-War adversaries to more diverse threats, whose novel characteristics have nullified traditional deterrence tactics. If some of these qualifications are not met, deterrence would be difficult, and preemption could be a realistic option, as Defender resorts to forestallment instead of punishment (Table 1). 


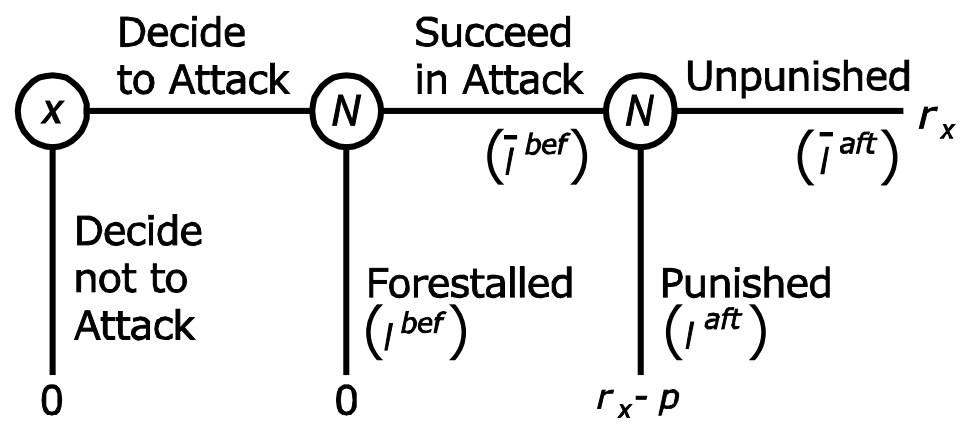

Figure 1. The flow of $x$ 's perpetration with his payoffs when $\alpha$ adopts (off-shore) policing

\section{The Model}

To figure out the factors that shape the form of policing, we develop a game-theoretic model that depicts a strategic situation, where Defender $\alpha$ seeks to police potential Perpetrators $x \in[0, X]$ aiming to attack $\alpha$ from abroad. ${ }^{9}$

\section{Off-Shore Policing}

To contain any Perpetrator $x$, Defender $\alpha$ may adopt preemptive and/or deterrent measures. By virtue of her intelligence agency, $\alpha$ can identify and find out each $x$ before (after) he commits perpetration with probability $I^{\text {bef }} \in(0,1)$ (I $\left.{ }^{a f t} \in(0,1)\right){ }^{10}$ That means, $\alpha$ can ward off $x$ 's attack preemptively with probability $I^{\text {bef }}$, and once she is attacked, $\alpha$ can punish the attacker $x$ with probability $I^{a f t}{ }^{11}$ For both preemption and punishment, $\alpha$ spends a per-case cost $c>0$, which is associated with mobilizing and dispatching her armed forces to $x$ 's sanctuary.

The game proceeds as follows:

1. Each Perpetrator $x$ decides (not) to attack Defender $\alpha$.

2. Before perpetration takes place, $\alpha$ decides (not) to forestall those identified $x$ who decided to attack $\alpha$ in 1.

3. After perpetration, $\alpha$ decides (not) to punish those identified $x$ who actually attacked $\alpha$.

The flow of $x$ 's perpetration when $\alpha$ adopts policing (which combines preemption and deterrence)

\footnotetext{
${ }^{9} X$ denotes $x$ 's population.

${ }^{10}$ Though unnecessary, it is natural that $I^{\text {bef }}<I^{a f t}$. It is presmably more difficult to identify a Perpetrator before an incident occurs than after.

${ }^{11}$ Practically, an intelligence agency can make wrongful charges (i.e., misjudging an innocent party as a perpetrator), but such a problem is abstracted away from our model as it is beyond our concern.
} 
appears in Figure 1. ${ }^{12}$

Each $x$ has its resolve $r_{x} \in \mathbb{R}^{+}$, which follows some distribution function $F(\cdot)$. (The resolve $r_{x}$ can be interpreted as $x$ 's benefit from attacking $\alpha$.) Given the cost $p>0$ of being punished by $\alpha, x$ decides to attack $\alpha$ if his resolve $r_{x}$ exceeds the expected cost $I^{a f t} p .{ }^{13}$ Thus, by $\alpha$ 's threat of punishment, the fraction $F\left(I^{a f t} p\right)$ of all $X$ Perpetrators are deterred, and the remaining $\bar{F}\left(I^{a f t} p\right)$ undeterred, where $\bar{F}\left(r_{x}\right) \equiv 1-F\left(r_{x}\right)$. (For notational convenience, we use the upper bar $\left(^{-}\right)$to denote the probability of the complement; i.e., for any probability $\operatorname{Pr}, \overline{\operatorname{Pr}} \equiv 1-\operatorname{Pr}$.) Out of the undeterrable Perpetrators who amount to $\bar{F}\left(I^{a f t} p\right) X$, the fraction $I^{\text {bef }}$ are precluded by $\alpha$ 's preemption, while those in the remaining fraction $\bar{I}^{\text {bef }}$ succeed in attacking $\alpha$ and inflicting a damage $d$ on $\alpha$, where $c<d .{ }^{14}$ Furthermore, among the $\bar{F}\left(I^{a f t} p\right) \bar{I}^{b e f} X$ attackers, the fraction $I^{a f t}$ are identified and punished.

Predicting Perpetrator $x$ 's behavior as above, Defender $\alpha$ chooses a means to counter Perpetrators. If she does not adopt any countermeasure and appears defenseless, her expected payoff would be: $\pi_{\alpha}^{n o} \equiv-X d$. Similarly, $\alpha$ 's expected payoffs from the three countermeasures can be derived as follows:

$$
\begin{aligned}
& \pi_{\alpha}^{p r e} \equiv-X\left(I^{b e f} c+\bar{I}^{b e f} d\right) \\
& \pi_{\alpha}^{\text {det }} \equiv-\bar{F}\left(I^{a f t} p\right) X\left(d+I^{a f t} c\right) \\
& \pi_{\alpha}^{p o l} \equiv-\bar{F}\left(I^{a f t} p\right) X\left(I^{b e f} c+\bar{I}^{b e f}\left(d+I^{a f t} c\right)\right),
\end{aligned}
$$

where $\pi_{\alpha}^{p r e}, \pi_{\alpha}^{\text {det}}$, and $\pi_{\alpha}^{\text {pol }}$ are $\alpha$ 's expected payoffs from preemption, deterrence, and policing, respectively. Apparently, $\alpha$ 's choice hinges on the accuracy of identification $\left(I^{\text {bef }}\right.$ and $\left.I^{\text {aft }}\right)$, the relative sizes of cost and damage on $\alpha(c$ and $d)$, the size of the threats to $\alpha(X)$, and $x$ 's decision calculus $\left(\mathrm{F}\left(r_{x}\right)\right.$ and $\left.p\right)$. Among the four alternatives, $\alpha$ adopts preemption whenever possible $\left(\pi_{\alpha}^{\text {pre }}>\pi_{\alpha}^{\text {no }}\right.$ and $\left.\pi_{\alpha}^{\text {pol }}>\pi_{\alpha}^{\text {det }}\right)$, because preemption is preferred to being attacked $(c<d)$.

In contrast to preemption, deterrence may not emerge immediately, because unlike preemption, a punishment itself brings no direct benefit to Defender - she has already been attacked anyway. In this sense, Defender may lack what justifies the cost of punishment, generating the commitment problem - it

12 In Figure 1, $N$ indicates "nature" which determines whether $x$ is identified or not. If only preemption (deterrence) is adopted, $I^{a f t}=0\left(I^{b e f}=0\right)$.

${ }^{13}$ To purify the effects of preemption and deterrence, we assume that preemption inflicts no cost on $x$ (generating no deterrent effect). If $x$ incurs the cost $p$ from preemption, a larger fraction $\bar{F}\left(I^{b e f} / \bar{I}^{b e f}+I^{a f t} p\right)$ of $x$ would be deterred.

${ }^{14}$ By $c<d, \alpha$ prefers her own preemption to $x$ 's perpetration. 
is often difficult for Defender to credibly convince potential Perpetrators of future retaliation (Bowen 2004: 59; Harvey 1998; Lebow 1981: 85-89; Levy 1988: 486; Wilner 2011: 31). This problem is plausible because $\alpha$ 's decision to punish $x$ is made only after the perpetration takes place.

In our model, the commitment problem can be resolved in a long-term context, where the game above is played repeatedly in successive time periods $t=1,2,3, \cdots .{ }^{15}$ To deter future perpetration, Defender must demonstrate her commitment by punishing the identified Perpetrators in every period. The success in deterrence thus necessitates her will and capability of producing such a demonstration effect, by which Perpetrators are informed and afraid of punishments caused by their deeds.

Put formally, the condition for credible punishments in the repeated game is:

$$
\bar{F}\left(I^{a f t} p\right) \bar{I}^{\text {bef }} I^{a f t} X c \leq\left(\frac{\delta}{1-\delta}\right)\left(\pi_{\alpha}^{p o l}-\pi_{\alpha}^{p r e}\right),
$$

where $\delta \in(0,1)$ is $\alpha$ 's discount factor for her future payoffs. By Condition (1), the cost of punishing the identified Perpetrators today (in the left-hand side, henceforth LHS) must not be so large as the present value of future deterrence (in the right-hand side, RHS).

In sum, off-shore direct policing emerges as a Subgame Perfect Nash Equilibrium (SPNE) - that we employ as the game's solution - with Condition (1):

Proposition 1: Defender $\alpha$ adopts off-shore direct policing over three other off-shore alternatives if and only if Condition (1) holds.

Proof: As any $x$ bases his decision (not) to attack $\alpha$ on the comparison between his resolve $\left(r_{x}\right)$ and the expected cost of being punished $\left(I^{a f t} p\right), \alpha$ 's expected payoffs from the four alternatives are determined as defined $\left(\pi_{\alpha}^{n o}, \pi_{\alpha}^{p r e}, \pi_{\alpha}^{d e t}, \pi_{\alpha}^{p o l}\right)$. Because $c<d, \pi_{\alpha}^{p r e}>\pi_{\alpha}^{n o}$ and $\pi_{\alpha}^{p o l}>\pi_{\alpha}^{d e t}$. Thus, policing is the best for $\alpha$ among the four alternatives if $\pi_{\alpha}^{p o l}>\pi_{\alpha}^{p r e}$, which is guaranteed by Condition (1), because its LHS is positive. In addition, Condition (1) suffices that $\alpha$ has the incentive to maintain her policing. Therefore, off-shore policing forms an equilibrium if Condition (1) holds. Condition (1) is necessary for the equilibrium as well.

By Condition (1), policing gives $\alpha$ the largest expected payoff among the four alternatives, but this game has multiple equilibria as with other repeated games. ${ }^{16}$ This multiplicity implies that off-shore

\footnotetext{
${ }^{15}$ A possible interpretation of this repeated game is that $X$ Perpetrators newly emerge every period.

16 Another (pure-strategy) equilibrium is mere preemption that takes place if any $x$ does not believe $\alpha$ 's punishments.
} 
policing casts doubt on the credibility of punishment for deterrence. The commitment problem emerges because Defender must dispatch her armed forces at the ex post cost $c$ in an ad hoc manner. One of the approaches to alleviating the problem is to reduce or eliminate $c$. On-shore policing, which we introduce next, is one of such approaches.

\section{On-Shore Policing}

With on-shore policing, Defender $\alpha$ stations her armed forces in the region, where Perpetrators $x$ hide themselves, in preparation for possible attacks. In doing so, $\alpha$ can demonstrate her resolve for policing by evading the ex post per-case cost $c$ and instead by sinking an ex ante lump-cost $C>0$ (Fearon 1997). ${ }^{17}$ That means, at the beginning of the game, which will no longer be repeated, $\alpha$ can commit herself to policing by paying the cost $C$ associated with stationing her armed forces near $x$ 's sanctuary. From on-shore policing, $\alpha$ expects her payoff to be:

$$
\pi_{\alpha}^{o n} \equiv-C-\bar{F}\left(I^{a f t} p\right) \bar{I}^{b e f} X d .
$$

On-shore policing forms an SPNE if it brings a larger expected payoff than off-shore policing:

Proposition 2: In comparison between on- and off-shore policing, $\alpha$ adopts the former if the lump-sum cost of on-shore policing $C$ is so small that $\pi_{\alpha}^{\text {on }}>\pi_{\alpha}^{\text {pol }}$, or

$$
C<\bar{F}\left(I^{a f t} p\right)\left(I^{b e f}+\bar{I}^{\text {bef }} I^{a f t}\right) X c .
$$

Proof: The proof of Proposition 2 is immediate from the comparison between $\pi_{\alpha}^{o n}$ and $\pi_{\alpha}^{p o l}$. Note that Condition (2) is sufficient but not necessary - even when on-shore policing is adopted, it can still be that $\pi_{\alpha}^{p o l}>\pi_{\alpha}^{o n}$ due to the commitment problem associated with off-shore policing (Condition (1)).

Condition (2) suggests that the relative advantage of on-shore policing depends on the size $\bar{F}\left(I^{a f t} p\right)\left(I^{b e f}+\bar{I}^{b e f} I^{a f t}\right) X$ of Perpetrators to police as well as the relative size between $C$ and $c$. On-shore policing makes more sense if the threats to counteract are greater.

In what follows, we will use on-shore policing as a benchmark for comparison across various forms of policing by assuming that on-shore policing is superior to any off-shore alternatives (i.e., $\pi_{\alpha}^{o n}>$ $\left.\max \left\{\pi_{\alpha}^{n o}, \pi_{\alpha}^{p r e}, \pi_{\alpha}^{d e t}, \pi_{\alpha}^{p o l}\right\}\right)$.

\footnotetext{
${ }^{17}$ An empirical study suggests that the success of deterrence hinges on the immediacy of counteraction against states (Huth and Russett 1988).
} 


\section{Indirect Policing}

Defender $\alpha$ may face economic, ethical, legal, physical, and political constraints that hinder her policing, especially preemption, abroad. In light of such constraints, Defender may use the state of Perpetrators' sanctuary, instead of herself, to police Perpetrators, if such Proxy-labelled as $\beta-\mathrm{s}$ better at policing them. This indirect policing can be induced positively (i.e., through reward).

To induce $\beta$ positively, $\alpha$ compensates $\beta$ for the cost of policing $C_{\beta}>0$, and $\alpha$ 's expected payoff is:

$$
\pi_{\alpha}^{i n d} \equiv-C_{\beta}-\bar{F}\left(I_{\beta}^{a f t} p_{\beta}\right) \bar{I}_{\beta}^{b e f} X d,
$$

where a subscript $i \in\{\alpha, \beta\}$ is added to parameters to indicate the associated player - there $\beta$ polices $x$ at cost $C_{\beta}$ paid by $\alpha$. (For simplicity, it is assumed that $\beta$ 's policing behavior and the associated cost $C_{\beta}$ are both observable to $\alpha \cdot{ }^{18}$ ) Then, $\alpha$ adopts indirect policing instead of direct policing if $\pi_{\alpha}^{\text {ind }}>$ $\pi_{\alpha}^{o n}$ :

Proposition 3: Indirect policing outperforms (on-shore) direct policing if it is so efficient (with a small $C_{\beta}$ ) and effective (with large $I_{\beta}^{\text {bef }}, I_{\beta}^{\text {aft }}$, and $p_{\beta}$ ) that

$$
C_{\alpha}-C_{\beta}>\left(\bar{F}\left(I_{\beta}^{a f t} p_{\beta}\right) \bar{I}_{\beta}^{\text {bef }}-\bar{F}\left(I_{\alpha}^{a f t} p_{\alpha}\right) \bar{I}_{\alpha}^{\text {bef }}\right) X d .
$$

Proof: The proofs of Propositions 3 and 4 are immediate from comparing payoffs at stake. For both propositions, $\beta$ has the incentive for policing, because $\beta$ 's cost of policing is covered by $\alpha$, so that $\beta$ 's payoff remains zero. Note that Condition (3) is sufficient but not necessary because of the possibility that $\pi_{\alpha}^{i n d}=\pi_{\alpha}^{o n}$

Condition (3) compares the relative cost (in the LHS) and effectiveness (in the RHS) of $\beta$ 's policing, implying that indirect policing can work if $\beta$ can police $x$ more efficiently and effectively than $\alpha$. The advantages of $\beta$ in policing may lie in her intelligence $\left(I_{\beta}^{b e f}>I_{\alpha}^{\text {bef }}\right.$ and $\left.I_{\beta}^{\text {aft }}>I_{\alpha}^{\text {aft }}\right)$ as well as the $\operatorname{cost}\left(C_{\beta}<C_{\alpha}\right)$ and severity $\left(p_{\beta}>p_{\alpha}\right)$ of punishments.

\section{Joint Policing}

If Defender $\alpha$ and Proxy $\beta$ counteract Perpetrators $x$ cooperatively, more effective policing might be expected. We call such a form of policing joint policing, from which $\alpha$ 's expected payoff is:

${ }^{18}$ This assumption will be relaxed in Online Appendix. 


$$
\pi_{\alpha}^{j o i} \equiv-C_{\alpha, \beta}-\bar{F}\left(I_{\alpha, \beta}^{a f t} p_{\alpha, \beta}\right) \bar{I}_{\alpha, \beta}^{b e f} X d,
$$

where $C_{\alpha, \beta}>0$ is the cost of joint policing; $p_{\alpha, \beta}>0$ is the effectiveness of joint punishment; ${ }^{19} I_{\alpha, \beta}^{\text {bef }}$ and $I_{\alpha, \beta}^{a f t}$ are the probabilities of ex ante and ex post identification of $x$, respectively. To define $\pi_{\alpha}^{j o i}$ as above, we assume positive inducement, by which $\alpha$ bears $\beta$ 's cost of policing. Joint policing would be a reliable option if $\alpha$ and $\beta$ can produce synergy effects. This can be formally stated as:

Proposition 4: Instead of policing alone (directly or indirectly), $\alpha$ and $\beta$ adopt joint policing if $\pi_{\alpha}^{j o i}>\max \left\{\pi_{\alpha}^{o n}, \pi_{\alpha}^{i n d}\right\}$, or for $i \in\{\alpha, \beta\}$,

$$
C_{i}-C_{\alpha, \beta}>\left(\bar{F}\left(I_{\alpha, \beta}^{a f t} p_{\alpha, \beta}\right) \bar{I}_{\alpha, \beta}^{b e f}-\bar{F}\left(I_{i}^{a f t} p_{i}\right) \bar{I}_{i}^{b e f}\right) X d .
$$

As Condition (4) suggests, joint policing is likely to be superior to either direct or indirect policing if (i) it exhibits the economies of scale $\left(C_{\alpha, \beta}<\min \left\{C_{\alpha}, C_{\beta}\right\}\right)$, (ii) joint punishments are effective $\left(p_{\alpha, \beta}>\right.$ $\left.\max \left\{p_{\alpha}, p_{\beta}\right\}\right)$, and (iii) $\alpha$ and $\beta$ have different pieces of information $\left(I_{\alpha, \beta}^{b e f}>\max \left\{I_{\alpha}^{b e f}, I_{\beta}^{b e f}\right\}\right.$; $\left.I_{\alpha, \beta}^{a f t}>\max \left\{I_{\alpha}^{a f t}, I_{\beta}^{a f t}\right\}\right)$.

\section{Reciprocal Policing}

So far we have presumed a unilateral situation, where Defender $\alpha$ is threatened by Perpetrators $x$ who reside in Proxy $\beta$ 's domain. In a bilateral situation, where both $\alpha$ and $\beta$ are threatened by Perpetrators in each other's domain, what we call reciprocal policing may emerge.

Suppose that there exists another group of potential Perpetrators $(y \in[0, Y]$ ), who are aiming to attack $\beta$ from $\alpha$ 's domain. Each of $y$ has his own resolve $s_{y} \in \mathbb{R}^{+}$, which follows a distribution function $G(\cdot)$, and a cost $q_{i}>0$ of being punished by state $i \in\{\alpha, \beta\}$. Each state $i$ can find out $y$ with probability $J_{i}^{b e f} \in(0,1)$ before $y$ 's attack and with probability $J_{i}^{a f t} \in(0,1)$ after it. ${ }^{20}$ By sinking a cost $D_{i}>0$, $i$ mobilizes her military to forestall and/or punish those identified $y$. (In short, $y$ 's $Y, s_{y}, G(\cdot), q_{i}$,

\footnotetext{
${ }^{19}$ It makes sense that $p_{\alpha, \beta}>\max \left\{p_{\alpha}, p_{\beta}\right\}$ if $\alpha$ and $\beta$ have different constraints on punishments. An industrial democracy (typically, $\alpha$ ) might enjoy more advanced technology but suffer more severe legal restrictions than an underdeveloped autocracy $(\beta)$.

${ }^{20}$ Any $y$ with $s_{y}>J_{i}^{a f t} q_{i}$ decides to attack $\alpha$.
} 
$J_{i}^{b e f}, J_{i}^{a f t}$ and $D_{i}$ correspond to $x$ 's $X, r_{x}, F(\cdot), p_{i}, I_{i}^{\text {bef }}, I_{i}^{\text {aft }}$ and $C_{i}$, respectively.) The damage $\alpha$ incurs from $y$ 's attack is assumed to be $d$.

One way to counteract these transnational Perpetrators $(x$ and $y)$ is that each state directly combats the threats to her own $-\alpha$ polices $x$, while $\beta$ does $y$. However, such a practice would be costly and cumbersome on the grounds that the states must dispatch and station their military units abroad. Policing would be easier and more efficient if the states tackle the threats harboring in their own domains for each other's sake instead - by reciprocal policing, $\alpha$ polices $y$, while $\beta$ does $x$.

In contrast to indirect and joint policing, which are induced positively, reciprocal policing requires no financial transfer to compensate the cost of each other's policing $\left(D_{\alpha}\right.$ and $\left.C_{\beta}\right)$. It instead relies on negative inducement - if a state fails to effectively police Perpetrators in its domain, it must bear a punishment, but this punishment takes the form of cessation of policing Perpetrators who target that state. Namely, if $\alpha$ fails to police $y, \beta$ would stop policing $x$, and vice versa. Thus reciprocal policing can be sustained if it is in the two states' long-term interests to police each other's threats.

In the repeated game, the conditions for reciprocity can be delineated as:

$$
\begin{aligned}
& D_{\alpha} \leq\left(\frac{\delta}{1-\delta}\right)\left(\pi_{\alpha}^{r e c}-\pi_{\alpha}^{o n}\right) \\
& C_{\beta} \leq\left(\frac{\delta}{1-\delta}\right)\left(\pi_{\beta}^{r e c}-\pi_{\beta}^{o n}\right),
\end{aligned}
$$

where $\delta$ is the discount factor of both $\alpha$ and $\beta ; \pi_{\beta}^{o n}$ is $\beta$ 's expected payoff from on-shore policing of $y\left(\pi_{\beta}^{o n} \equiv-D_{\beta}-\bar{G}\left(J_{\beta}^{a f t} q_{\beta}\right) \bar{J}_{\beta}^{b e f} Y d\right)$; and $\pi_{i}^{r e c}$ for $i \in\{\alpha, \beta\}$ is $i$ 's expected payoffs from reciprocal policing:

$$
\begin{aligned}
& \pi_{\alpha}^{r e c} \equiv-D_{\alpha}-\bar{F}\left(I_{\beta}^{a f t} p_{\beta}\right) \bar{I}_{\beta}^{b e f} X d \\
& \pi_{\beta}^{r e c} \equiv-C_{\beta}-\bar{G}\left(J_{\alpha}^{a f t} q_{\alpha}\right) \bar{J}_{\alpha}^{b e f} Y d .
\end{aligned}
$$

In regard to Condition (5), for instance, if $\alpha$ shirks policing $y, \beta$ will not police $x$, so that $\alpha$ must directly police $x$ on her own (with her payoff $\pi_{\alpha}^{o n}$ ). By Conditions (5) and (6), the two states protect each other to garner each other's protection. Conditions (5) and (6) also suggest that because reciprocal policing requires states to have long-term interests, it would be difficult if the states' administrations were politically unstable.

Proposition 5: Reciprocal policing can form an SPNE if and only if Conditions (5) and (6) hold. 
Proof: Reciprocal policing is better than no policing or on-shore policing for both $\alpha$ and $\beta$ (i.e., $\pi_{i}^{r e c}>\pi_{i}^{o n}$ for $i \in\{\alpha, \beta\}$ ), because $D_{\alpha}$ and $C_{\beta}$ in Conditions (5) and (6) are both positive. Moreover, $\alpha$ and $\beta$ have the incentives for reciprocal policing if Conditions (5) and (6) hold. These conditions are necessary as well.

While Proposition 5 focuses on a bilateral situation, it can be immediately expanded to a multilateral situation, where more than two states are concerned with transnational Perpetrators dispersed across multiple states. 
Table 2. List of Perpetrators' characteristics and their hampering effects on the tasks for policing

\begin{tabular}{lccc}
\hline & Threatening & Investigation & $\begin{array}{c}\text { Forestallment } \\
\text { Punishment }\end{array}$ \\
\hline Agility & - & - & $\bigcirc$ \\
Easiness of perpetration & - & $\bigcirc$ & $\bigcirc$ \\
Foreign sovereignty & - & $\bigcirc$ & $\bigcirc$ \\
Geography & - & $\bigcirc$ & $\bigcirc$ \\
Intrinsic value & $\bigcirc$ & $\bigcirc$ & $\bigcirc$ \\
Language & $\bigcirc$ & $\bigcirc$ & - \\
Plurality & $\bigcirc$ & - & - \\
Lack of C3 system & $\bigcirc$ & - & - \\
Lack of representative & $\bigcirc$ & -
\end{tabular}

\section{Advantages and Disadvantages}

The critical difference among the four forms of policing lies in the allocation of the tasks for policing (i.e., threatening, investigation, and punishment for deterrence; investigation and forestallment for preemption) between Defender and Proxy. The allocation determines the advantages and disadvantages of each of the four forms, which we elucidate below in line with our formal analyses.

\section{Direct Policing}

Policing of Perpetrators is often difficult for Defender, because they have novel characteristics that hamper Defender's tasks for policing. Perpetrators' characteristics potentially obstructive to policing are listed as follows:

- Agility. Perpetrators who can move and rove in an agile way may not be easily detected and grasped. Agility also raises the cost of punishment by expanding the risk of collateral damages (as with hellfire missiles launched from combat drones flying in Pakistan).

- Easiness of perpetration. As the cost of perpetration falls, it can become more escalated. In extreme situations, it is committed without deliberation (e.g., a cracker's tapping of F5 for Denial-of-Service attacks).

- Geography. Some Perpetrators are protected by geographic barriers. They may hide themselves in the depth of forests, caverns, or mountains. 
- Intrinsic value. A disparity in value between Defender and Perpetrators can cause errors in communication and mistakes in choosing a punitive target (Bowen 2004). Moreover, Perpetrators are immune to the threat of punishment if they have no tangible value to hold dear (Gray 2003; Payne 2003; Trager and Zagorcheva 2005/06). ${ }^{21}$

- Language. The difference of language between Defender and Perpetrators can provoke a failure in threatening unless a diplomatic or other channel of communication is established. It may also hinder investigation.

- Plurality. If there are a number of (potential) Perpetrators with similar characteristics such as crackers, it is difficult for Defender to identify the true culprit among them. Different threats to different targets can cause confusion as to who is really threatened.

- Foreign sovereignty. If Perpetrators are harbored in foreign territory, Defender is hampered from conducting an investigation and imposing a punishment (Bowen 2004). ${ }^{22}$

- Lack of C3 system. The system of command, control, and communication functions to carry through Perpetrators' unified will. Without it, some members of Perpetrators' group may act against the will of their leadership. Some terrorist networks, including al-Qaeda, appeared to lack the system (Sageman 2008: 146).

- Lack of representative. A representative is needed for both external and internal relations. Externally, he is to receive the threat of punishment hurled by Defender. Internally, he may assume leadership in a group to integrate its members' opinions and make a collective decision.

The effects of these characteristics on the tasks for policing are summarized in Table $2 .{ }^{23}$ These obstacles tend to make Defender's investigation inaccurate (with small $I^{\text {bef }}$ and $I^{\text {aft }}$ ), forestallment and punishment costly and ineffective (with large $c$ and small $p$ ), exacerbating the commitment problem especially when Defender seeks to deter Perpetrators off the shore (Proposition 1).

Note that the effects of these characteristics on policing are determined not solely by Perpetrators per se but also by their relations to Defender. That means, these effects can be weakened if policing is delegated

\footnotetext{
21 Even fanatical terrorists may have return addresses (Steinberg 2001).

${ }^{22}$ Even the most elusive terrorists require permissive state environments (Gray 2003: 453). A state may also passively sponsor terrorism (Byman 2005).

${ }^{23}$ Because we build our theory on rational-choice grounds, we intentionally put aside Perpetrators' irrationality, which is apparently another causal factor of deterrence failure. (Imagine drug-addicted rebel leaders in the Sierra Leone Civil War during the 1990s). Irrationality undermines deliberate decision-making and accurate communication.
} 
to another party. On these grounds, indirect policing has a potential to effectively police elusive Perpetrators when they are deemed not directly policeable.

\section{Indirect Policing (Advantages)}

In light of Perpetrators' obstructive characteristics, Defender can hardly fulfill the tasks for policing. It then makes sense for Defender to rely on a third party (Proxy) who is in a better position to influence Perpetrators. This is when indirect policing appears as a serious choice. Although the literature finds the merit of indirect deterrence in the third party's influence, the sources of the influence have not been explored in a systematic manner. ${ }^{24}$ We offer a functional account of why Proxy can be more influential on Perpetrators than Defender and more fundamentally why indirect policing can outperform direct policing.

Below we explore the sources of Proxy's influence that are closely associated with the tasks for policing.

Proxy as a Liaison: Communicative Advantage

Proxy has the advantage in communicating with Perpetrators, which can be explained twofold. The first argument concerns the credibility of threats. As a sovereign state of the region, Proxy may enact criminal laws and strengthen enforcement agencies to prepare and enable various kinds of punishments in an explicit and consistent manner. A criminal justice system strongly signals Proxy's commitment to the enforcement of laws. These threats by laws are naturally more credible than threats by Defender, whose forces are distanced from Perpetrators in peacetime and mobilized only in an ad hoc manner to carry out punishments. From a more theoretical standpoint, because Proxy has presumably been closer to Perpetrators, Proxy has a strong incentive to develop and maintain his reputation among Perpetrators, and this reputation effect can contribute to the credibility of his threats. ${ }^{25}$

The second argument regards the channel to hurl threats. Proxy can make use of the local media to publicize the conditions and severity of punishments. Moreover, when threatening Perpetrators, Proxy can evade some of the obstacles caused by Perpetrators' characteristics—especially those of intrinsic value and language - that Defender cannot. This is because Proxy, as their host, plausibly shares the same or similar ascriptive backgrounds with Perpetrators.

\footnotetext{
${ }^{24}$ To be fair, some scholars address Proxy's informational advantage (that we explain below), while others emphasize Proxy's capabilities of stopping assistance or supplies to Perpetrators. However, unlike us, they do not offer a rational-choice account of indirect deterrence. For informational advantage, see Gray 2003, 453-454; Heymann 2001/02, 36. For assistance and sponsorship, see Bar 2008; Byman 2005; Colby 2008; Lebovic 2007: 117-124; Miller 2013; Smelser and Mitchell 2002; Whiteneck 2005.

${ }^{25}$ With the reputation effect, even cheap talk can be a credible threat (Sartori 2007).
} 


\section{Proxy as a Detective: Informational Advantage}

Policing requires investigation-identifying the true culprit among (potential) Perpetrators and finding out what he holds dear. Investigation is difficult for Defender if Perpetrators possess obstructive characteristics (Table 2). However, this informational problem can be alleviated if Defender delegates the task to Proxy, who is closer to Perpetrators so as to monitor them more thoroughly $\left(I_{\beta}^{b e f}>I_{\alpha}^{b e f}\right.$ and $I_{\beta}^{a f t}>I_{\alpha}^{a f t}$ ). If the host government (i.e., Proxy) is well-functioning, at least some obstacles such as language, geography, and foreign sovereignty can be substantially reduced or eliminated.

With indirect policing, Defender does not have to identify the culprit by herself; she merely has to determine Proxy in charge and attribute the culprit's misdeed to Proxy. The culprit then is to be identified and punished by Proxy instead. If international norms and laws stipulate that the host government is in charge, it suffices that Defender finds out the state where Perpetrators reside and lets its government police them. In this sense, by adopting indirect policing, Defender can reduce the identification problem to the attribution problem. In the context of indirect policing, identification is not synonymous with attribution. Given Proxy's informational advantage, attribution demands much less efforts than identification.

Proxy as an Executor: Offensive Advantage

Proxy also has the advantage in both forestallment and punishment. Because Proxy is geographically closer to Perpetrators than Defender, he may fulfill both preemptive and deterrent operations more effectively and efficiently $\left(p_{\beta}>p_{\alpha}\right.$ and $\left.C_{\beta}<C_{\alpha}\right)$.

Defender's forestallment may be constrained if Perpetrators are stationed in another country's territory, because it tramples down the host state's sovereignty. Defender's military involvement can naturally invite political hardships such as protests from the local populace and counterattacks by Perpetrators. ${ }^{26}$ Thus, in many instances, preemption is politically infeasible for Defender. However, Defender can still resort to preemption if she delegates the task to Proxy. ${ }^{27}$ By doing so, Defender may circumvent political damages that preemption generates. Preemption by the government of the region at stake (Proxy) can be perceived as more legitimate than preemption by an outsider (Defender).

Punishment is also easier for Proxy than for Defender. By stipulating punishments in criminal laws, Proxy can impose various kinds of punishments. ${ }^{28}$ Various punishment options enable what strategists

\footnotetext{
${ }^{26}$ U.S. drone campaigns in Pakistan's Federally Administered Tribal Areas have infuriated citizens.

27 The aerial application of chemicals, as induced by the U.S., to eradicate coca plants in Colombia can be regarded as an instance of indirect preemption.

${ }^{28}$ Cheap punishments include ostracism and boycotting. For instance, Osama Bin Laden was purged by the Saudi
} 
call "graduated deterrence" (Buzzard 1956; Freedman 2004: 35; Nitze 1956). Even when deterrence fails at an early stage, Proxy can still retain options of more severe punishments to deter the escalation of perpetration. On the contrary, Defender must face difficulties with imposing punishments because of the physical distance. A punishment farther away from its target takes more cost and time. Off-shore deterrence is known to be much less effective, because the cost of mobilizing forces casts doubt on the credibility of threats and also because delayed punishments are not so threatening for impatient or present-minded deterrees. $^{29}$

\section{Indirect Policing (Disadvantages)}

The disadvantages of indirect policing stem from Defender's delegation of policing to Proxy. Inefficiency may occur at least in two scenarios if Defender has limited information about Proxy. In one, Defender cannot observe Proxy's choice. In the other, Defender does not know Proxy's cost of policing. Both scenarios result in overcompensation-Defender ends up paying more than the true cost of policing. Below we informally outline the problems. ${ }^{30}$

If Defender cannot directly observe Proxy's choice of policing, Defender's payment to Proxy must be based on his policing outcome (or equivalently the number of attacks) rather than his choice. However, if there exists a possibility $(\varepsilon>0)$ of failure in policing, Proxy must bear the risk $\varepsilon$ of being unpaid. To compensate for this risk, Defender must pay for the associated premium if Proxy is risk-averse. Given that Proxy faces severe financial constraints without solid political support (as in many developing countries), it is not unnatural that Proxy is sensitive to such a risk.

Moreover, uncertainty about the cost of policing generates another kind of inefficiency. If Defender does not know whether Proxy's cost of policing $C_{\beta}$ is low $\left(C_{\beta}^{L}>0\right)$ or high $\left(C_{\beta}^{H}>C_{\beta}^{L}\right)$, Defender must pay the high $\operatorname{cost} C_{\beta}^{H}$ to ensure Proxy's policing no matter how unlikely the high cost is. In other words, without the information about the $\operatorname{cost} C_{\beta}$ (i.e., Proxy's "type"), Defender would overcompensate the cost of policing with a substantial likelihood $\left(\operatorname{Pr}\left(C_{\beta}^{L}\right)\right)$. This overcompensation is needed-otherwise, Proxy would not do policing in case with $C_{\beta}^{H}$-generating inefficiency.

Defender's ample aid to Proxy, as caused by the informational problems above, may merely corrupt

\footnotetext{
government.

${ }^{29}$ While the immediate or short-term balance of forces favors the defender, the long-term balance of forces does not (Huth and Russett 1988).

${ }^{30}$ Formal analyses are left in Online Appendix, where the model is extended to incorporate informational discrepancies between Defender and Proxy.
} 
Proxy to satisfy his personal greed, sacrificing public needs. (Recall also Mobutu Sese Seko's “Versailles of the Jungle" in Congo or Imelda Marcos' thousands of pairs of shoes in the Philippines.) ${ }^{31}$ Regarding the U.S. War on Drugs in Mexico, the U.S. Congress's opposition to assisting Mexico in fighting the War implies its skepticism toward the aid's usefulness (Lacey 2008). Even worse, Proxy may use this "rent" to wipe out his political enemies brutally. ${ }^{32}$ Both corruption and tyranny could provoke hostile reactions from citizens. If Proxy continues to abuse his power for his own ends, his populace may become discontented and even question his legitimacy. As Proxy's administration loses civilian support, it could be replaced by an anti-Defender junta, ideologist party, or extremist organization, resulting in Defender's loss of influence there. In fact, the U.S. experienced the downfall of its sympathizer administrations and the rise of its challengers in the third world-Iraq, Cuba, Libya, South Vietnam, Iran, Nicaragua, Grenada, Egypt, and Somalia, all of which once adopted more or less pro-U.S. policies. ${ }^{33}$

\section{Joint Policing}

Because joint policing is conducted by both Defender and Proxy instead of just one or the other, it can be more effective than either direct or indirect policing. Put concretely, Defender and Proxy together can find out Perpetrators more accurately $\left(I_{\alpha, \beta}^{\text {bef }}>\max \left\{I_{\alpha}^{\text {bef }}, I_{\beta}^{\text {bef }}\right\}\right.$ and $\left.I_{\alpha, \beta}^{\text {aft }}>\max \left\{I_{\alpha}^{\text {aft }}, I_{\beta}^{\text {aft }}\right\}\right)$ and punish them more severely $\left(p_{\alpha, \beta}>\max \left\{p_{\alpha}, p_{\beta}\right\}\right.$ for punishment). In addition, joint policing can also achieve more efficiency (i.e., $C_{\alpha, \beta}<\min \left\{C_{\alpha}, C_{\beta}\right\}$ ), because specialization can occur between them. To suppress the insurgency by ISIL, for instance, the U.S. has focused its resources mainly on satellite surveillance and air raids, while Iraq has advanced its troops on the ground. Because the U.S. and Iraq face different sorts of constraints, they naturally seek and adopt different tactics. To eradicate the Japanese piracy, in another instance, China and Japan implicitly divided the tasks geographically. While the Chinese Ming court banished the pirates roving the Chinese coast, the Japanese shogunate quashed their home strongholds (Tanaka 2012: 76-77). The division of tasks in these instances had a potential to reduce the cost of policing.

Despite these advantages, joint policing is not always an option for Defender. The collaboration may not

\footnotetext{
${ }^{31}$ According to the U.N. Monitoring Group on Somalia, weapons and ammunition supplied by the U.S. to the Somali government were sold for cash and ultimately fell into the hands of the terrorist organization, al Shabab (Scahill 2013: 476).

32 Abuses of human rights were reported in the operations of Plan Colombia and Merida Initiative (Olson and Wilson 2010). One might also consider Operation Condor of the 1970s, in which right-wing juntas aimed to eradicate communists in several South-American states.

${ }^{33}$ It is apparently too hasty to attribute these regime changes solely to U.S. intervention, but at the same time, it is probably too naïve to deny the U.S. influence in these regions.
} 
produce the synergy effects mentioned above if policing by either Defender or Proxy is severely constrained by some of economic, ethical, geographic, legal, political, or technological obstacles (Table 2).

\section{Reciprocal Policing}

Reciprocal policing formulates a collective security regime that can be mutually beneficial for the participating states. Because each state can focus on policing Perpetrators within its domain, this regime tends to enhance efficiency $\left(C_{\beta}<C_{\alpha}\right.$ for $x ; D_{\alpha}<D_{\beta}$ for $\left.y\right)$ as well as effectiveness $\left(I_{\beta}^{b e f}>I_{\alpha}^{\text {bef }}\right.$, $I_{\beta}^{a f t}>I_{\alpha}^{a f t}$, and $p_{\beta}>p_{\alpha}$ for $x ; J_{\alpha}^{b e f}>J_{\beta}^{b e f}, J_{\alpha}^{a f t}>J_{\beta}^{a f t}$, and $q_{\alpha}>q_{\beta}$ for $y$ ). In addition, because policing is induced negatively (i.e., with a threat of penalty), no financial transfer is required. Consequently, the inefficiency associated with the private information in delegation (i.e., overcompensation) does not emerge in reciprocal policing. Instead, it may suffer the so-called free-rider problem - the incentive for policing may be impaired especially when many states take part in the regime. For instance, despite having a red notice from Interpol, Paul Watson of the Sea Shepherd has not been detained for years but has appeared to the media and to the public, suggesting Interpol's inability to work in accordance with its member state's laws. ${ }^{34}$ The free-rider problem also arises from the lack of a monitoring mechanism. In fact, the unverifiability of compliance is exactly the reason that the U.S. has been a consistent opponent of arms control in cyberspace (Clarke and Knake 2010: 219). ${ }^{35}$ As with Five Eyes, a selective membership may alleviate this problem.

\footnotetext{
34 Paul Watson even overtly attended the Cannes Film Festival in 2015.

35 Arms control in cyberspace includes the prevention of cybercrimes. During the Cold War, the Soviet Union agreed to a multilateral ban on biological weapons, but then secretly went on to create a massive biological weapons arsenal that the U.S. did not detect (Clarke and Knake 2010: 222).
} 


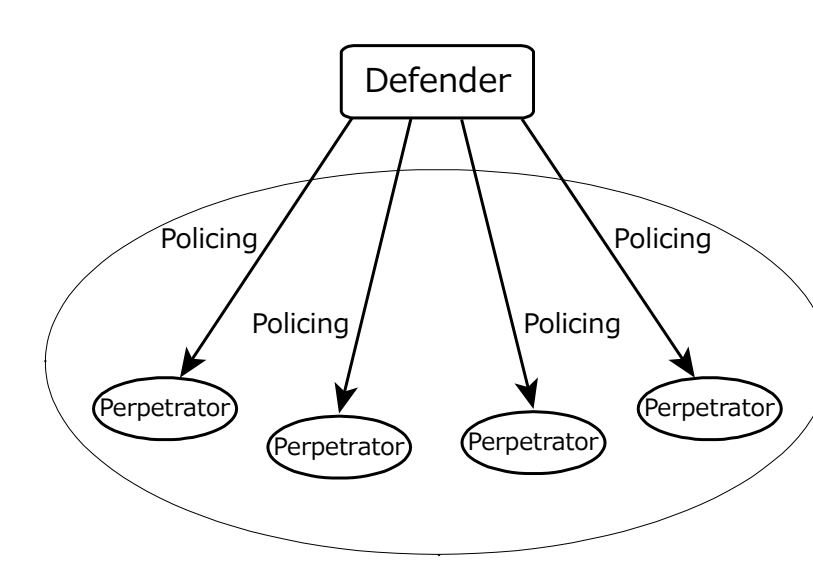

(a) Direct policing

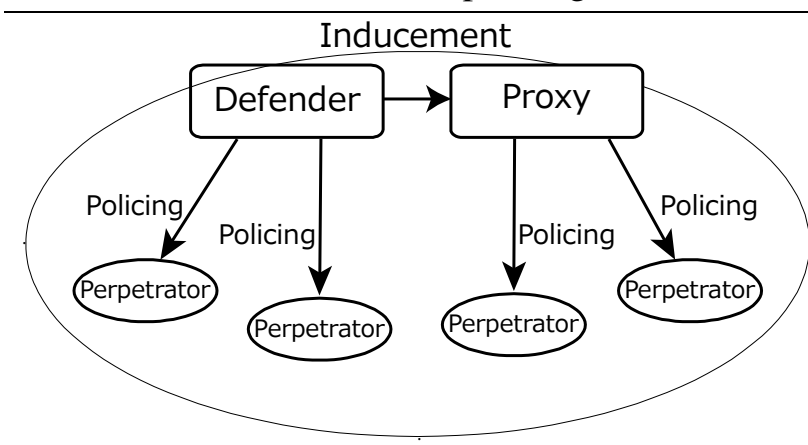

(c) Joint policing

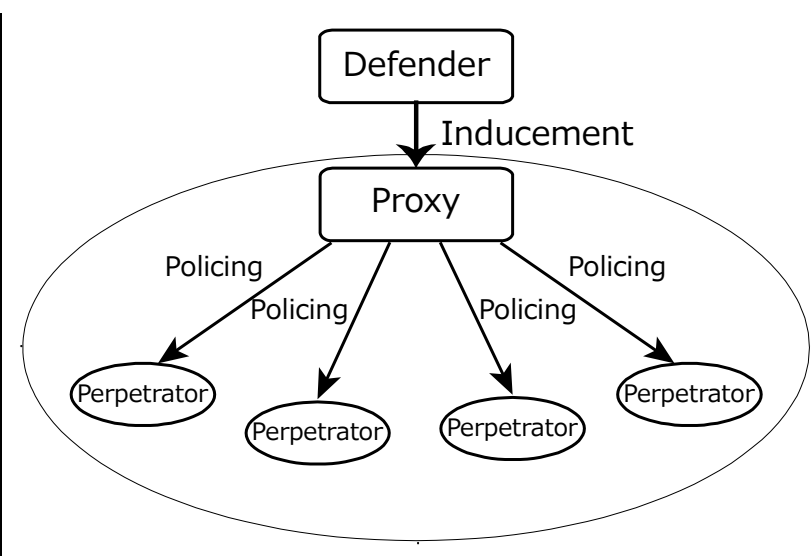

(b) Indirect policing

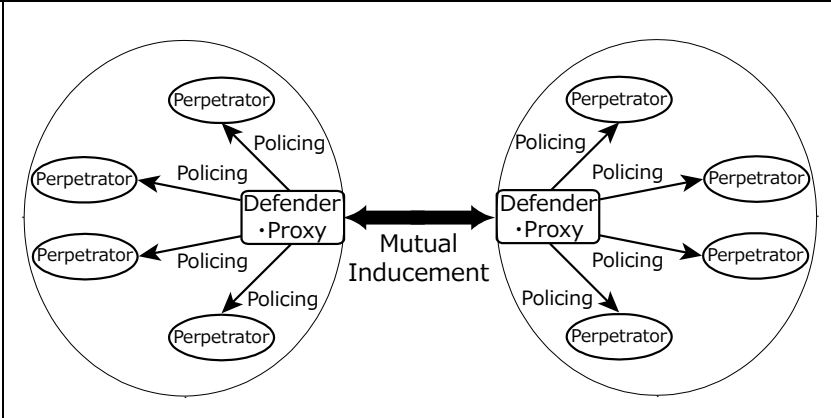

(d) Reciprocal policing

Figure 2. Forms of transnational policing

\section{Incidents}

We have categorized the practices of transnational policing into four forms (Figure 2). We delineate them using associated historical and contemporary incidents.

\section{Direct Policing}

If there is no reliable candidate for Proxy, Defender has no other option than policing Perpetrators on her own, or she must tolerate them. The U.S. drone strikes against al-Qaeda, Taliban, and other terrorist groups in Pakistan's Federally Administered Tribal Areas, Yemen, and Somalia since 2002 largely fall in this category (Scahill 2013: 78). So does the command targeting Osama bin Laden (Operation Neptune Spear). We group these instances of policing solely by Defender into what we call direct policing. Defender may police Perpetrators from her home (off-shore policing) or from their vicinities (on-shore policing), but other things being equal, off-shore policing will have more difficulties with producing and demonstrating her commitment to policing (Proposition 1), as implied by the lack or rarity of effective counter-perpetration measures by the U.S. until the 9/11 attacks (Bowen 2004). This form of policing is 
often conducted by multiple Defenders, as found in the anti-piracy campaigns off the Somali coast since 2008 (Combined Task Force 151).

\section{Indirect Policing}

To implement indirect policing, Defender must determine Proxy who is capable of controlling Perpetrators but is still within her influence. This condition is plausible when Proxy is a sovereign state that is substantially less powerful—very often economically and militarily—-than Defender. One instance of indirect policing is the U.S. prosecution of the War on Drugs in Colombia and Mexico during the 2000s (Plan Colombia and Merida Initiative). ${ }^{36}$ Honoring these states' sovereignty, the U.S. refrained from, or at least limited, her own military engagements in their territory, but it instead focused on supporting the governments of Colombia and Mexico to eradicate drug cartels nested there. The U.S. assistance of the Philippine government in fighting Moro Islamic Liberation Front, Abu Sayyaf, Jemaah Islamiyah, and other insurgent groups is another instance (Operation Enduring Freedom - Philippines), where the U.S. involvement was limited to financing, advising, training, and equipping the Armed Forces of the Philippines. ${ }^{37}$

\section{Joint Policing}

Defender may fight Perpetrators jointly with Proxy. That is, Defender combines direct and indirect policing for greater efficacy and effectiveness. This joint policing is likely when Proxy is cooperative but incapable of fighting alone. For instance, the coalition of the willing, consisting of the U.S. and its allies, initiated air raids on ISIL in 2014 but remained deliberate in provoking battles on the ground. This Operation Inherent Resolve is naturally interpreted as the coalition's attempt to eradicate the ISIL leadership, but it can also be seen as the coalition's reinforcements for the Iraqi Security Forces and the Kurdish militia in their fights against ISIL (Gordon 2015; Schmidt and Schmitt 2016). The Operation thus includes both direct and indirect features. Another instance of joint policing can be found in Israel's policies toward the Palestinian Authority and Arab terrorists after the Second Intifada. Israeli Prime Minister Ariel Sharon harshly suppressed the insurgency, but meanwhile he pressured Palestinian

\footnotetext{
36 Long before Plan Colombia, successive U.S. administrations have assisted the Colombian government in prosecuting the War on Drugs (e.g., Andean Initiative of 1990), but its assistance was punctuated when the Colombian government was uncooperative, notably when Ernesto Samper was in power (implicated in the Proceso 8000 scandal). This change of U.S. attitude toward Colombia indicates that the U.S. attempted to manipulate Colombia's anti-drug policies through incentives.

37 Joint Special Operations Task Force - Philippines 2011: "U.S. forces are temporarily deployed to the Philippines in a strictly non-combat role to advise and assist the Armed Forces of the Philippines."
} 
President Yasser Arafat to stop it by conditioning the negotiation for peace on the cessation of terrorist attacks (Miller and Wines 2002). The lead episode about China and the Japanese pirates in the medieval era also illustrates a feature of joint policing. While China's Ming government repeatedly requested Japan's shogunate to control the pirates, China itself fought and effectively defeated them in 1419, after which Japanese piratical activities declined drastically (Tanaka 2012: 77) ${ }^{38}$

Note that the three forms of policing listed above are conceptually distinctive, but their boundaries are practically ambiguous. Defender often controls the degree of her direct involvement, depending on how effectively Proxy can police Perpetrators. In its pursuit of Operation Enduring Freedom, for instance, the U.S. has deliberately chosen the extent of its own military engagements, based on the power of the local authorities and the severity of the insurgency. Its engagement is intensive in Yemen and Somalia-as exemplified by the deployment of combat drones-but very moderate in the Philippines - where it is restricted mainly to advising and training. ${ }^{39}$ In addition, the gradual withdrawal of U.S. troops from Iraq and Afghanistan, as the regional security stabilizes, can be interpreted as the transition from joint policing to indirect policing in our language. The subsequent re-deployment of the U.S. Air Force to counter the rise of ISIL in Iraq and Syria can also be seen as the transition in reverse. It is not very meaningful to ask when the transition is complete. It is rather a matter of the degree of balance between direct and indirect policing.

\section{Reciprocal Policing}

If Perpetrators are dispersed across several states, international cooperation is essential to police them, because every state has severe legal, physical, and economic constraints in fighting abroad. It thus makes sense that these states establish a mechanism of reciprocal policing to enhance security. As a state joins the mechanism, it is liable for protecting other states from transnational perpetration originating from its own domain, while being protected by other states elsewhere. Namely, each state assumes the roles of Defender as well as Proxy. As our model suggests, this mechanism can work if a defecting state is subject to exclusion or other forms of penalty (Proposition 2). An instance of reciprocal policing is the U.N. Security Council Resolution 1540, which mandates all the member states to establish legal and

\footnotetext{
38 Japan's shogunate had originally refused China's requests during its civil strife. It initiated a piracy expedition only after the shogunate achieved its political reunification, suggesting that Proxy's local influence is one of the critical determinants in shaping the form of policing (So 2004: 3-4). China's diplomacy ultimately worked (Tanaka 2012: 76).

39 In Yemen, the U.S. adopted indirect measures as well as direct ones (Scahill 2013: 65, 234-236, 322, 386). Even in Somalia, the U.S. aided the government that failed long ago (Scahill 2013: 476). Nonetheless, we regard these instances as direct policing, because direct policing overwhelmed the indirect form there.
} 
regulatory measures against the proliferation of weapons of mass destruction. Other variants of reciprocal policing can be found in Interpol, Five Eyes, ${ }^{40}$ Budapest Convention, ${ }^{41}$ Shanghai Cooperation Organization, ${ }^{42}$ and Cyber War Limitation Treaty (CWLT). ${ }^{43}$ Retrospectively, the notorious

U.S. Fugitive Slave Laws of 1793 and 1850, which materialized the protection of the slave ownership nuanced in Article IV of the U.S. Constitution, also played a similar role. ${ }^{44}$ These Laws facilitated inter-state coordination in capturing and returning escaped slaves to their owners.

\footnotetext{
${ }^{40}$ Five Eyes is an Anglo-Saxon intelligence alliance, comprising the U.S., the U.K. Canada, Australia, and New Zealand.

${ }^{41}$ Drawn up by the Council of Europe, the Budapest Convention is the first international treaty on cybercrime (effective July 1, 2004).

${ }^{42}$ The Shanghai Cooperation Organization was founded by China, Russia, Kazakhstan, Kyrgyzstan, and Tajikistan in 2001 to promote regional security in Eurasia. Its members share their concerns about terrorism, separatism, extremism, and cross-border crimes (Shanglin 2006).

${ }^{43}$ To date, CWLT remains hypothetical but is an apparent application of our reciprocal policing to fighting cyber-crimes. According to Clarke and Knake (2010: 270), "Non-state actors will be a problem for cyber arms control, but CWLT should shift the burden of stopping them to the states party to the convention. Nations would be required to rigorously monitor for hacking originating in their country and to prevent hacking activity from inside their territory."

${ }^{44}$ The Fugitive Slave Clause in Article IV: "No Person held to Service or Labour in one State, under the Laws thereof, escaping into another, shall, in Consequence of any Law or Regulation therein, be discharged from such Service or Labour, but shall be delivered up on Claim of the Party to whom such Service or Labour may be due."
} 


\section{Conclusion}

Various concepts of deterrence have been developed over the past few decades (cf. Freedman 2004: 24-42). One of the questions to explore in the next stage would be which measures are most suitable to counteract which adversaries. We have tackled this question by focusing on direct and indirect approaches to preemption and deterrence against transnational perpetrators.

Deterrence of transnational perpetrators is often difficult, because they are too disorganized to fulfill their unified will, too obscure to be identified and detected, or too fanatical to have secular value. Deterrence of transnational perpetrators must comprise of three tasks-threatening, investigation, and punishment —which accordingly mandate four qualifications for deterrers-resolve, communication, intelligence, and capability - as well as three qualifications for deterrees-unity, visibility, and return address. The three tasks for deterrence can be hampered by novel characteristics inherent in transnational perpetrators-agility, easiness of perpetration, foreign sovereignty, geography, intrinsic value, language, and plurality as well as the lack of $\mathrm{C} 3$ system and representative-that impair the qualifications for deterrees (Table 2). With recognition of these characteristics, we maintain that the obstacles to deterring them can be overcome if Defender-instead of directly deterring Perpetrators-makes use of a third party (Proxy) who is in a better position to influence Perpetrators. We call this tactic by Defender indirect policing on the grounds that Proxy may engage in preemption as well as deterrence.

To explain why indirect policing can outperform direct policing, we have developed a game-theoretic model that offers a functional threefold account of Proxy's influence: (a) as a liaison, or a conveyer of threats, Proxy can convince Perpetrators of the terms and severity of punishments more credibly than Defender (communicative advantage); (b) as a detective, or a monitor of Perpetrators, Proxy is better at identifying Perpetrators and finding out what they hold dear (informational advantage); (c) as an executor, or an enforcer of rules, Proxy can cripple and punish Perpetrators more effectively and more efficiently (offensive advantage). By utilizing Proxy's functional advantages, Defender can indirectly police Perpetrators whom she cannot police directly.

Despite its functional advantages, indirect policing is no panacea. The delegation of policing can cause inefficiency-Defender must pay more than the true cost of policing (i.e., overcompensation)—if Defender cannot observe Proxy's choice and/or cost of policing. This inefficiency may make Proxy corrupted and tyrannical, possibly destabilizing his regime. The fragility of Proxy's regime is 
exemplified by the downfall of pro-U.S. administrations that occurred in the Third World during the Cold War. Moreover, states may lack the incentive for reciprocal policing (free-rider problem). ${ }^{45}$

With an eye to associated historical and contemporary incidents, we offer taxonomy of policing in four forms (Table 3): (i) direct policing, that is, Defender preempts and/or deters perpetration abroad without a third party's reinforcement (e.g., Somali counter-piracy); (ii) indirect policing, by which Defender induces Proxy to police Perpetrators (U.S. War on Drugs in Colombia and Mexico); (iii) joint policing, which combines direct and indirect policing (Operation Inherent Resolve); (iv) reciprocal policing, in which each Defender-Proxy state polices Perpetrators in its territory (Interpol).

Reverting to the question of when indirect policing outperforms its direct counterpart, we maintain that the relative success of indirect policing hinges on which advantages or disadvantages are critical in its operation. The pros and cons of each counter-perpetration policy should be examined when policymakers adopt one out of alternatives. Policymaking must depend on how perpetrators' characteristics impede policing and how these impediments can be overcome.

As we have shown, transnational policing is far from rare in history but has been largely overlooked. We shed light on its mechanism and build a formal theory for it upon empirical grounds. With the rise of transnational perpetrators - a trend that, we believe, is very likely to continue in the future-transnational policing should be theoretically more refined, empirically more scrutinized, and perhaps practically more institutionalized.

\footnotetext{
45 Indirect policing can also generate two communicative problems. One is caused by the "Chinese-whispers" form of sequential communication from Defender to Proxy and from Proxy to Perpetrators. The other is the complexity in Defender's inducement of Proxy that must specify the "when," "what" and "how" of the demanded behavior (Schelling 1966: 72-73). These problems can make communication slow and erroneous.
} 
Table 3. Taxonomy of policing

\begin{tabular}{|c|c|c|c|c|}
\hline Policing & Direct (off-shore) & Indirect & Joint & Reciprocal \\
\hline Policer & Defender & Proxy & Defender \& Proxy & Two or more states \\
\hline Inducement & No & Positive & Positive & Mutual \& negative \\
\hline Advantages & $\begin{array}{c}\text { No delegation } \\
\text { of policing }\end{array}$ & $\begin{array}{c}\text { Threatening; } \\
\text { Intelligence; } \\
\text { Offense }\end{array}$ & $\begin{array}{c}\text { Threatening; } \\
\text { Intelligence; } \\
\text { Offense }\end{array}$ & $\begin{array}{c}\text { Threatening; } \\
\text { Intelligence; } \\
\text { Offense; } \\
\text { No financial transfer }\end{array}$ \\
\hline Disadvantages & $\begin{array}{c}\text { Obstacles to } \\
\text { policing }\end{array}$ & Overcompensation & Overcompensation & Free-riding \\
\hline Incidents & $\begin{array}{l}\text { U.S. drone strikes } \\
\text { against al Qaeda }\end{array}$ & U.S. War on Drugs & $\begin{array}{c}\text { U.S.-Iraq } \\
\text { against ISIL }\end{array}$ & Interpol \\
\hline
\end{tabular}




\section{References}

Atzili, Boaz, and Wendy Pearlman. 2012. "Triadic Deterrence: Coercing Strength, Beaten by Weakness.” Security Studies. 21(2): 301-335.

Bar, Samuel. 2008. "Deterring Terrorism: What Israel Has Learned.” Policy Review. 149: 29-42.

Betts, Richard K. 2002. "The Soft Underbelly of American Primacy: Tactical Advantages of Terror." Political Science Quarterly. 117(1): 19-36.

Bowen, Wyn Q. 2004. "Deterrence and Asymmetry: Non-State Actors and Mass Casualty Terrorism." Contemporary Security Policy. 25(1): 54-70.

Buzzard, Anthony. W. 1956. "Massive Retaliation and Graduated Deterrence." World Politics. 8(2): 228-237.

Byman, Daniel. 2005. "Passive Sponsors of Terrorism.” Survival. 47(4): 117-144.

Carter, David B. 2012. “A Blessing or a Curse? State Support for Terrorist Group.” International Organization. 66(1): 129-151.

Clarke, Richard A., and Robert K. Knake. 2010. Cyber War: The Next Threat to National Security and What to Do about It. New York: HarperCollins Publishers.

Colby, Elbridge. 2008. "Expanded Deterrence: Broadening the Threat of Retaliation." Policy Review. 149: 43-59.

Davis, Paul K., and Brian Michael Jenkins. 2002. Deterrence \& Influence in Counterterrorism: A Component in the War on al Qaeda. Santa Monica, CA: RAND.

Davis, Paul K., and Brian Michael Jenkins. 2004. "A System Approach to Deterring and Influencing Terrorists." Conflict Management and Peace Science. 21(1): 3-15.

Fearon, James D. 1997. “Signaling Foreign Policy Interests: Tying Hands versus Sinking Costs.” Journal of Conflict Resolution. 41(1): 68-90.

Freedman, Lawrence. 2004. Deterrence. London, UK: Polity Press.

Forero, Juan. 2003. "Colombia Rebels Admit Kidnapping 3 Americans After Crash.” New York Times. February 23.

George, Alexander L. 2002. "The Need for Influence Theory and Actor-Specific Behavioral Model of Adversaries." In Barry R. Schneider and Jerrold M. Post, eds. Know Thy Enemy: Profiles of Adversary Leaders and Their Strategic Cultures. Maxwell Air Force Base, AK: United States Air Force Counterproliferation Center.

Gordon, Michael R. 2015. "Kurds, Backed by U.S. Air Power, Try to Regain Sinjar From ISIL.” New York Times. November 12.

Gray, Colin. 2003. "The Reformation of Deterrence: Moving On.” Comparative Strategy. 22(5): 429-461. 
Harvey, Frank. 1998. "Rigor Mortis or Rigor, More Tests: Necessity, Sufficiency, and Deterrence Logic.” International Studies Quarterly. 42(4): 675-707.

Heymann, Philip B. 2001/02. "Dealing with Terrorism: An Overview." International Security. 26(3): 24-38.

Huth, Paul, and Bruce Russett. 1988. "Deterrence Failure and Crisis Escalation.” International Studies Quarterly. 32(1): 29-46.

Isacson, Adam. 2005. "Failing Grades: Evaluating the Results of Plan Colombia." Yale Journal of International Affairs. Summer/Fall: 138-154.

Joint Special Operations Task Force - Philippines. 2011. "U.S. Ambassador Visits JSOTF-P in Southern Philippines." March 24.

Knopf, Jeffrey W. 2008. "Wrestling with Deterrence: Bush Administration Strategy after 9/11." Contemporary Security Policy. 29(2): 248-253.

Knopf, Jeffrey W. 2012. "Terrorism and the Fourth Wave in Deterrence Research." In Andreas Wenger and Alex Wilner, eds. Deterring Terrorism: Theory and Practice. Stanford, CA: Stanford University Press.

Kroenig, Matthew, and Barry Pavel. 2012. "How to Deter Terrorism.” Washington Quarterly. 35(2): 21-36.

Lebovic, James H. 2009. Deterring International Terrorism and Rogue States: US National Security Policy After 9/11. New York: Routledge.

Lebow, Richard Ned. 1981. Between Peace and War: The Nature of International Crisis. Baltimore, MD: Johns Hopkins University Press.

Levy, Jack S. 1988. "Review Article: When Do Deterrent Threats Work?” British Journal of Political Science. 18(4): 485-512.

Miller, Gregory D. 2013. “Terrorist Decision Making and the Deterrence Problem.” Studies in Conflict \& Terrorism. 36(2): 132-151.

Miller, Judith, and Michael Wines. 2002. "Sharon Tentatively Backs Plan for Palestinian State." New York Times. December 5.

Mote, Frederick W. 1999. Imperial China: 900-1800. Cambridge, MA: Harvard University Press.

Nitze, Paul. H. 1956. “Atoms, Strategy, and Policy.” Foreign Affairs. 34(2): 187-198.

Olson, Eric L. and Christopher E. Wilson. 2010. "Beyond Merida: The Evolving Approach to U.S.-Mexico Security Cooperation.” Working Paper Series on U.S.-Mexico Security Cooperation. Trans-Border Institute, University of San Diego.

Payne, Keith B. 2003. "The Fallacies of Cold War Deterrence and a New Direction." Comparative Strategy. 22(5): 411-428. 
Reuter, Peter, Gordon Crawford, and Jonathan Cave. 1988. Sealing the Borders: The Effects of Increased Military Participation in Drug Interdiction. Santa Monica, CA: RAND Corporation.

Sageman, Marc. 2004. Understanding Terror Networks. Philadelphia, PA: University of Pennsylvania Press.

Sageman, Marc. 2008. Leaderless Jihad: Terrorist Networks in the Twenty-First Century. Philadelphia, PA: University of Pennsylvania Press.

Salehyan, Idean. 2009. Rebels without Borders: Transnational Insurgencies in World Politics. Ithaca: Cornell University Press.

Sandler, Todd, and Kevin Siqueira. 2006. “Global Terrorism: Deterrence Versus Pre-Emption.” Canadian Journal of Economics. 39(4): 1370-1387.

Sartori, Anne R. 2007. Deterrence by Diplomacy. Princeton, NJ: Princeton University Press.

Scahill, Jeremy. 2013. Dirty Wars: The World Is a Battlefield. New York: Nation Books.

Schelling, Thomas C. 1966. Arms and Influence. New Haven, CT: Yale University Press.

Schmidt, Michael S., and Eric Schmitt. 2016. "U.S. Plans to Step Up Military Campaign Against ISIS." New York Times. April 17.

Shanglin, Luan. 2006. "SCO to Intensify Fight against Cross-Border Drug Crimes." China View. April 22.

Smelser, Neil J., and Faith Mitchell, eds. 2002. Discouraging Terrorism: Some Implications of 9/11. Washington D.C.: National Academies Press.

Steinberg, Gerald M. 2001. "Rediscovering Deterrence After September 11, 2001." Jerusalem Letter/Viewpoints. No. 467(17).

Stokes, Doug. 2005. America's Other War: Terrorizing Colombia. New York: Zed Books.

Tanaka, Takeo. 2012. Wakou: Umi no Rekishi [Japanese Pirates: History of the Sea]. Tokyo, Japan: Kodansha.

Trager, Robert F., and Dessislava P. Zagorcheva. 2005/06. "Deterring Terrorism: It Can Be Done.” International Security. 30(3): 87-123.

Whiteneck, Daniel. 2005. "Deterring Terrorists: Thoughts on a Framework." Washington Quarterly. 28(3): 187-199.

Wilner, Alex S. 2011. "Deterring the Undeterrable: Coercion, Denial, and Delegitimization in Counterterrorism.” Journal of Strategic Studies. 34(1): 3-37. 